\title{
THE NERVES OF THE THYROID AND PARATHYROID BODIES
}

\author{
DARMON A. RHINEHART
}

From the Laboratory of Anatomy, Indiana University

FIVE FIGURES

Prior to the year 1867 the nerves of the thyroid were usually described as vaso-motor for the supply of the numerous blood vessels.

Peremeschko ('67) examined thin teased preparations of thyroid that had been maccrated in acetic acid and water, and found many more nerves than the gland was thought to contain. He described some of these as following the arteries, and others as leaving the vessels, dividing again and again, and finally losing themselves as fine varicosed branches in the interfollicular connective tissue.

Poincaré ('75), after macerating the gland in dilute acetic acid colored with fuchsin, found abundant nerves and nerve plexuses, which he considered to be a separate nerve supply for this organ, connected with the central system by the nerves entering the gland. He also described ganglion cells lying in groups or clumps either in the substance of the larger nerves, in the nerves at their places of branching, or alongside the nerve stems.

Anderson (94) described the formation of very elaborate perivascular plexuses from which fine fibers penetrate between the follicles and form perifollicular plexuses in which the follicles seem to be imbedded. These nerves are very irregular in their course, do not anastomose, and, after repeated divisions, the terminal fibrillae end in knobs on the bases of the cells. At no time do they enter the cells nor do they penetrate between them.

Berkeley ('95) described perivascular plexuses similar to those of Anderson, and a primary and secondary plexus surrounding 
each follicle, the former lying some distance from the bases of the cells, the latter directly on the cells. Small curved branches from the secondary plexuses end in knobs and look as if they penetrate between the cells while others are straight indicat ng that their endings lie on the basal ends of the cells.

Crissafulli's (92) description of these nerves agrees in almost all particulars with that of Anderson, with the exception that he found ganglion cells here and there throughout the gand.

\section{TECHNIQUE}

The only technical methods for staining nerve fibers that were found of value in this work were the intra-vitam methylene blue method of Ehrlich and the Golgi method.

The methylene blue method was carefully tried in all its forms, but was only valuable in staining the larger nerves accompanying the blood vessels into the gland.

The original Golgi method in the rapid and mixed form together with the modification of Berkeley gave poor results. The most successful and complete staining of the nerves was secured by the use of the 'double impregnation' method of Cajal, modified as to the length of time the tissues were allowed to remain in the different fluids.

This method consists in fixing small pieces of tissue for from six to eight days in a mixture made up of four parts of a 3.5 per cent solution of potassium bichromate and one part of a 1 per cent solution of osmic acid. After fixation and a careful washing in distilled water the tissues are put into a 1 per cent solution of silver nitrate for three days. This is followed by a second fixation for an additional three days, and a second impregnation with silver. After the first day in the second silver solution free hand sections are examined at intervals until the norves are found to be satisfactorily stained. The tissues are then rapidly dehydrated in several changes of 95 per cent and absolute alcohol, and are quickly imbedded in celloidin, the blocks being hardened in chloroform. Sections, 25 to 100 microns thick, are cut under oil, cleared on the slides in carbol-xylol and xylol, and mounted 
in thick xylol-balsam. The slides should then be warmed until enough of the xylol has evaporated to leave the balsam brittle on cooling, and while still warm, covered by warmed cover slips. Preparations prepared in this way are permanent.

\section{THE NERVES OF 'THE THYROID}

The nerves which go to the thyroid are entirely of the nonmedullated variety and reach it from the neighboring cervical sympathetic ganglia by following the perivascular connective tissue and the tunica adventitia of the thyroid arteries. It is often very difficult to examine these nerves, for they are obscured in sections stained by the chrome silver method by large amounts of black and brown precipitates, and by the staining of the fat. By carefully examining sections where there is only a small amount of fat, or better, by studying sections stained by the methylene blue method, the nerves accompanying the blood vessels can be followed. They appear as large, wavy, irregular strands, composed of individual varicosed axis-cylinders collected together into bundles similar to the wires in a cable.

These nerves do not branch elaborately outside the gland; the only branches coming from them are small ones which form the perivascular plexuses in the arterial walls, and probably furnish the vaso-motor supply. As soon as the arteries penetrate into the gland substance they branch profusely, this branching being accompanied by a corresponding branching of the nerves, so that as the arteries decrease in size there is a similar decrease in the size of the accompanying nerves. The nerves supplying these smaller arteries (fig. 2) form an elaborate perivascular plexus, and give off the branches which penetrate between the follicles, and form the perifollicular plexuses. The latter are the only ones that can be said to be the true glandular or secretory nerves.

The arterial or perivascular plexuses are formed by the branches of a few relatively large nerve trunks (fig. $2, A$ ), lying in the connective tissue immediately surrounding the vessels, and having a course parallel to that of the arteries. The branching from these nerves is very irregular; the branches taking any direction after 
leaving the main trunk. They extend for a longer or shorter distance around the vessels, divide again and again, and finally become resolved into an intricate network of fine end fibrillae. This elaborate nervous plexus is located in the perivascular connective tissue and in the tunica adventitia of the arterial walls, while some of the finer fibrillae penetrate into the tunica media.

The larger nerves are composed of bundles of axis-cylinders, and the branching of these consists merely in some of these axiscylinders leaving the main bundle and taking a different direction. As this method of branching continues the axis-cylinders finally come to lie singly. From these single fibers are given off true branches, which do not decrease in size but are usually more irregular, more varicosed, and have a more wavy course. The final end fibrillae are often very short, are beset with many varicosities, and soon end in irregular enlargements or end-knobs.

The many crossings and recrossings of the nerves, together with their elaborate branching, is very misleading, and often gives the appearance, especially under low magnification, of true anastomoses. In the thicker sections where the nerves are great in number it is often impossible to distinguish the separate fibers. But if relatively thin sections are examined under high magnification the fibers can all be traced individually. Therefore, contrary to the statement of Berkekey, true anastomoses do not occur. In examining these nerves it is seen that the origin and ending of the most of the branches cannot be traced in a single section for they are only fragments, the remainder having been cut away.

All the nerves that go to make up the perivascular plexuses are more or less varicosed. Even the axis-cylinders that form the large nerve bundles are beset with many irregular enlargements. There may also be precipitations of chrome-silver between the axis-cylinders in places, so as to give the nerves the appearance of solid cords. At the points of branching of all the nerves there are irregular, triangular, black masses, which may be either a portion of the nervous structure or a black precipitate. The smaller nerves, where the axis-cylinders lie singly, are more varicosed than the corresponding parts of the larger nerves; this 
being especially true of the final end fibrillae. In fact these nerves appear as if consisting of many irregular enlargments connected by fine threads (fig. 4). The varicosities may be only slightly larger than the fibers or they may be twice as large; the larger ones are cylindrical, spherical, or irregularly triangular, the majority, however, are either oval or spindle-shaped.

The final endings of the nerves consist of fine end branches. The smallest fibers usually divide into two, sometimes more, end fibrillae. The course of these fibrillae is very irregular, they are very varicosed and soon end. The tip consists of a spindleshaped enlargement or end-knob. This ending sometimes occurs in the perivascular connective tissue, sometimes in the tunica adventitia, but most often in the tunica media in relation to the smooth muscle fibers of the vessel walls. Occasionally endings from the perivascular plexuses can be seen penetrating the perivascular connective tissue and terminating in relation with the bases of the epithelial cells of the immediately adjacent follicles.

The plexus surrounding the arteries is more dense and complex than that surrounding the accompanying veins. The venous plexus resembles the arterial in formation and architecture but it is not nearly as elaborate. The peri-capillary plexus is usually formed from the few end branches of a single fiber, running parallel to the course of the vessel.

The most important nerves of the thyroid from a physiological standpoint are those that have their endings in intimate relation to the gland cells, for they are the true glandular or secretory nerves. These nerves pass into the gland substance alongside of, or in the walls of the arteries, together with those that form the perivascular plexuses and furnish the vaso-motor supply. They assist in the formation of the perivascular plexuses but there is no way of distinguishing them from the vaso-motor nerves. There may be, however, a physiological difference in the two kinds of nerves, but if such exists, it cannot be determined histologically.

As has been said before, the nerves do not leave the large arteries and pass directly into the gland substance, for this does not occur until the vessels, by branching, have decreased very much in 
size. From the perivascular plexuses of these smaller arteries are given off here and there nerves which penetrate into the interfollicular connective tissue for a greater or lesser distance and form the perifollicular plexuses. These branches are almost always single fibers, for none of the larger nerves leave the vessels as such.

The perifollicular plexuses completely surround all of the follicles of the thyroid, or, as Anderson has said, there is present a diffuse plexus of nerves in which the follicles scem to be imbedded (fig. 3) The nerves coming from the perivascular plexuses may supply a follicle near the artery, they may supply one at a considerable distance, or their branches may enter into the formation of the plexuses of several follicles. These nerves divide again and again into a large number of fine, varicosed fibers which completely surround a single follicle or adjacent follicles in a dense nervous network. There is absolutely no regularity, arrangement or method in the place or manner of branching, nor in the direction the branches may take after leaving the main stem. Neither is there any regularity in the distribution of the glandular nerves, nor anything that can be said of their distribution, except that they enter into the formation of the plexuses around one or more of the follicles of the thyroid. There are no primary or secondary plexuses, as described by Berkeley, but a single one surrounding each follicle.

In regard to the anastomoses of the nerves of these plexuses the same statement applies that was made in regard to the perivascular nerves. In the thinner sections the nerves can all be traced as individuals, and the branches can be traced to the parent stem if it is included in the section.

The perifollicular nerves are also very varicosed, the varicosities corresponding in size and shape to those found on the nerves of the perivascular plexuses.

Perhaps the most important fact to be determined concerning the nerves of the thyroid is the position and manner of the final endings of the follicular nerves, for the effect of nervous impulses on the secretory activity of the gland cells would depend, to a great extent, on the intimacy of the relations of the nerves to them. 
The presence or absence of a definite basement membrane around the follicles is an important point in regard to nerve and cell relations. The majority of investigators are of the option that a definitely formed basement membrane is absent, but that there is a condensation of the connective tissue immediately surrounding the follicles, and this gives support to the bases of the epithelial cells (Baber).

The final endings of the nerves are short, fine, very varicosed fibrillae which lie in this condensed connective tissue (figs. 1 and 4). Some of these end fibrillae are curved, as described by Berkeley, while others are straight, and still others, and perhaps a majority, are irregular. They always end in a knob-like enlargement on the basal ends of the cells; each cell, however, does not come into relation with the end of a nerve, but only a few scattered here and there throughout the follicles. I have been unable, by most carefully examining a large number of sections with the best magnification obtainable, to see any of these endings either entering the cells or penetrating into their intercellular substance.

In some of the literature concerning the nerve supply of the thyroid the statement is made that ganglion cells were found in different locations within the gland. Anderson and Berkeley, however, with whom I agree, state that these structures are not present. Thereare, in many of the sections stained by the chromesilver method, numbers of black precipitations which resemble ganglion cells very closely in size and shape and could easily be mistaken for them. A careful examination of many of these does not reveal anything resembling a nucleus or nucleolus, while even if nerve fibers enter them, the arrangement is not characteristic of ganglion cell processes.

\section{THE NERVES OF THE PARATHYROID}

A careful examination of all the literature accessible concerning the parathyroid has failed to reveal any reference whatever to its nerve supply, and one of the latest histologies makes the statement that this subject needs further investigation.

The technique used in investigating the nerves of the parathyroid was the double impregnation method of Cajal as given in 
detail elsewhere in this paper. Several of these small bodies were carefully dissected out and carried through separately, but with poor results. Those sections of the parathyroid in which the nerves are the most abundant are attached to some of the more satisfactorily stained sections of thyroid. The treatment in both cases is, therefore, identical.

The first and most striking thing observed on examination of these sections of parathyroid is the scarcity of the nerves as compared to the great numbers found in the thyroid. It would at first seem that this might be due to incomplete staining, which is not at all probable, for in the adjacent thyroid tissue partially or completely surrounding the parathyroid, the nerves are beautifully stained. The similar density of the two bodies leads me to believe that a method giving a satisfactory result in one would lead to a like result in the other.

The arteries supplying the parathyroid bodies are branches of the thyroid arteries, and may take either or both of two routes in reaching their places of distribution. When the bodies are not closely connected there is one relatively large branch that passes directly into the parathyroid, but when the thyroid partially or completely surrounds the parathyroid, more numerous but smaller branches take origin from the thyroid vessels within the thyroid gland and pass through the intervening small amount of loose connective tissue into the parathyroid. Inasmuch as the nerves follow these arteries, they arise from the large nerve bundles around the thyroid vessels and accompany their branches into the parathyroid. It is very probable, thercfore, that the nerves supplying both glands constitute a single set of sympathetie fibers.

Around the parathyroid arteries there are formed nerve plexuses resembling the perivascular plexuses of the thyroid vessels, differing, however, in not being nearly so elaborate, and in consisting of single fibers. The branching of the nerves accompanies the branching of the arteries, so that the smaller arterial twigs usually carry with them a single nerve fiber. There are no nerves around the veins or capillaries. 
In most instances the nerves can be traced along the vessel wall, within which are also found their few terminal branches. A few other fibers are present which cannot be followed along a vessel, but which seem to run in the connective tissue between the groups and cords of gland cells. It is probable, however, that these accompany smaller vessels which are too poorly stained to be visible. I am of the opinion that the nerves are entirely vasomotor for the supply of the blood vessels, and that there are no special glandular or secretory nerves in the parathyroid, because none of the fibers leave the supporting connective tissue and penetrate into the cell groups.

\section{CONCLUSIONS}

1. The nerves of the thyroid are entirely non-medullated and reach it from the cervical sympathetic ganglia by following the thyroid arteries.

2. In the thyroid there are formed elaborate nervous plexuses around all the blood vessels and all the follicles, the nerves forming the latter coming from the plexuses surrounding the smaller arteries.

3. The perivascular nerves end in the walls of the blood vessels and furnish the vaso-motor supply, while those of the perifollicular plexuses end on the bases of the epithelial cells and probably carry impulses influencing secretion.

4. All the nerves are varicosed but do not anastomose.

5. The nerves of the parathyroid come from the same set that supplies the thyroid and pass into it along with the branches from the thyroid arteries. These nerves probably all end in the vessel walls and are vaso-motor in function.

6. No ganglion cells are found in either the thyroid or parathyroid bodies. 


\section{BIBLIOGRAPHY}

Anderson, Oskar A, 1894 Zur Kenntniss der Morphologie der Sehilddrüse. Arehiv für Anatomie und Physiologie, Anat. Abt.

BABER, E. C. 1876 and 1881 Contributions to the minute anatomy of the thyroid gland of the dog. Phil. Trans. of the Royal Society of London; vol. 166 , part 2; vol. 172, part 3.

Berkelex, Henry J. 1895 Nerves of the thyroid gland of the dog. Johns Hopkins Hospital Reports, vol. 4.

Grissafulut, E. 1892 I Nervi della Glandola Tiroide. Bulletino mens. della Acad. Gioenia si scienz. nat. in Catania. Nuova Serie, Fasc. 25.

Dogiel, A. S. 1910 Methylenblau zur Nervenfärbung. Enzyklopadie der mikroskopischen Technik, Band 2, Berlin.

Hardesty, Irving 1902 Neurological technique. Chicago.

Huber, G. Card 1892 Zur Technik der Golgi'schen Methode. Anatomischer Anzeiger., Band 7.

Kaluius 1910 Golgisehe Methode. Enzyklopadie der mikroskopischen Technik, Band 1.

Major, Ralph H. 1909 Studies on the vascular system of the thyroid gland, Amer. Jour, Anat., vol. 9.

Peremeschko 1867 Ein Beitrag zum Bau der Schilddrüse. Zeitschrift für wissenschaftliche Zoologie, Band 8.

Poincane 1875 Note sur l'innervation de'la glande thyroide. Journal de l'anat. et de la phys., Tome 11.

WiLson, J. Gondon 1910 Intra vitam staining with methylene blue. Anat. Rec., vol. 4, no. 7, July. 


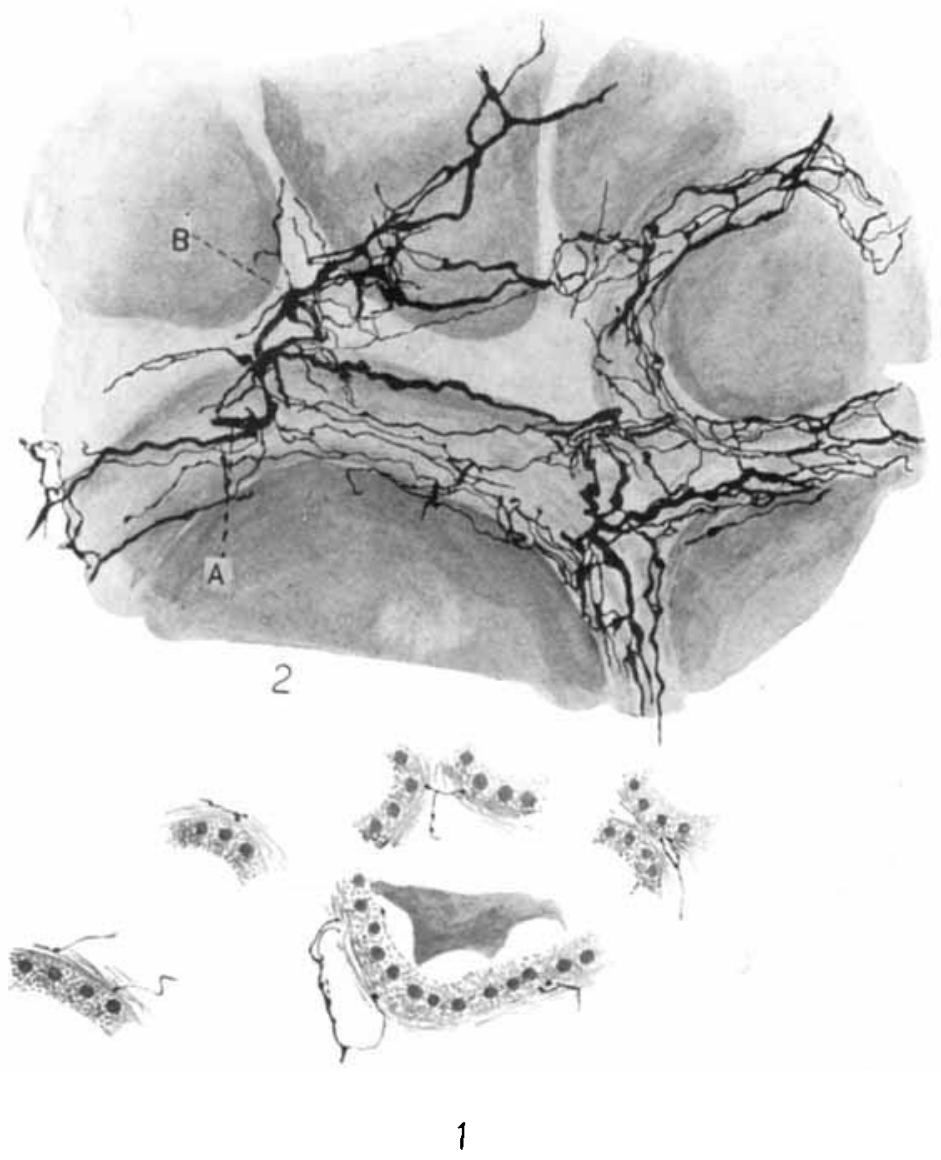

All drawings were made with an Edinger drawing apparatus using Leitz compens oculars nos. 4 and 6 , and 4 and $16 \mathrm{~mm}$. apochromatic objectives.

Fig. 1 Drawing showing the relation of the nerve endings to the gland cells. $\times 650$.

Fig. 2 A small artery in the interior of the thyroid showing the elaborate perivascular plexus. $A$, large nerve bundle breaking up to form the plexus; $B$, nerve leaving the perivascular plexus to form the perifollicular plexus. $\times 630$. 


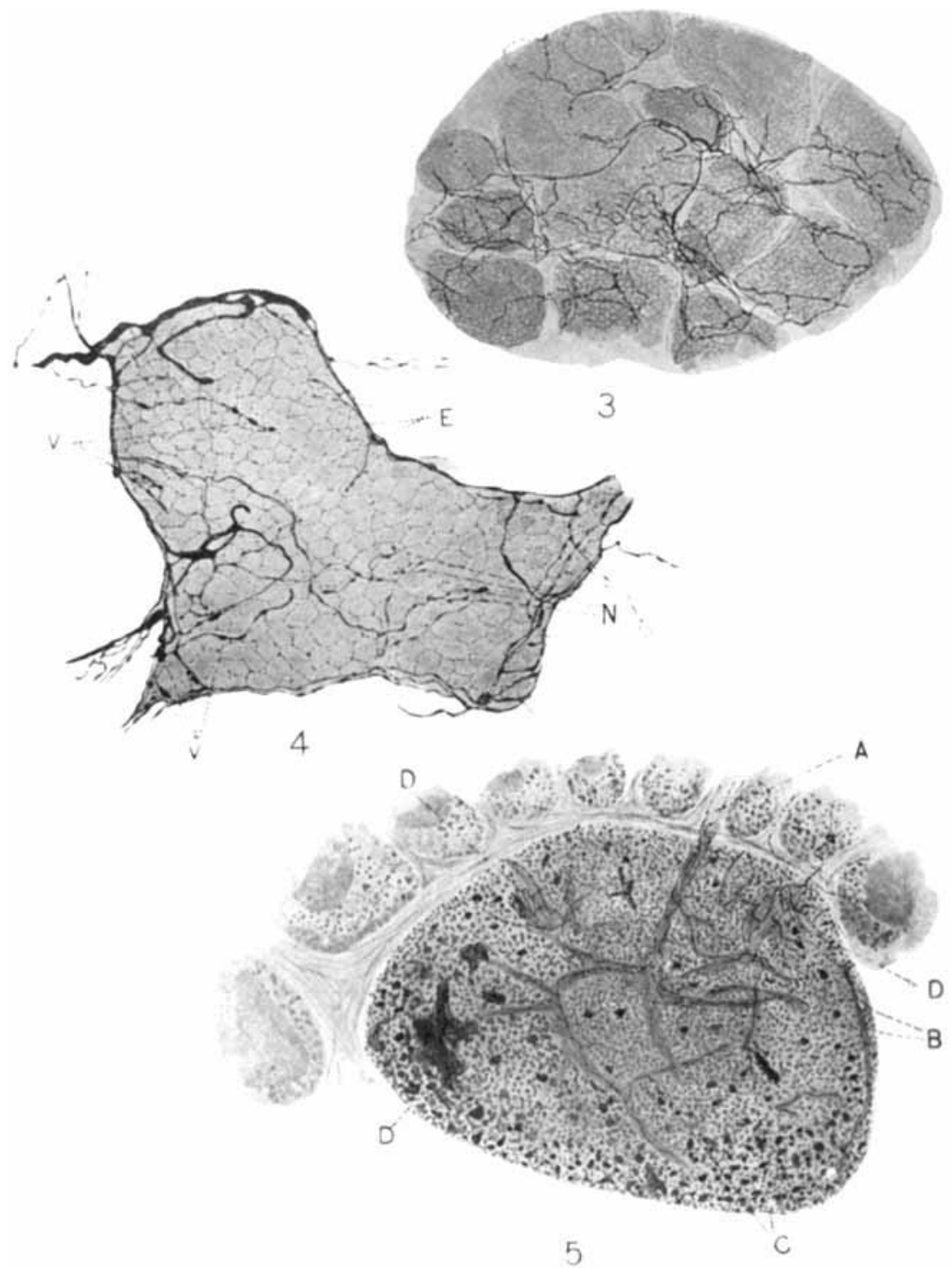

Fig. 3 Several adjacent follicles showing the intimate connections of the adjacont perifollicular plexuses. $\times 250$.

ligg. 4 One of the follicles shown in fig. $3 . \quad N$, endings of the follicular nerves; $V$, varicositios on the nerves; $R$, the epithelial cells, the intercellular substance stained a light brown. $\times 650$.

Fig. 5 Section of the parathyroid. $A$, small artery accompanied by nerves entering the paratbyroid from the thyroid; $B$, supporting connective tissue: $C$. nerves in this connective tissue; $D$, nerve endings. $\times 150$. 